\title{
MEDIAÇÃO SANITÁRIA, UM OLHAR PARA O DIREITO À SAÚDE À LUZ DO DIRITTO VIVENTE
}

\author{
Sandra Regina Martini ${ }^{1}$ \\ Ana Luísa Michelon ${ }^{2}$
}

\section{Resumo}

A jurisdição não tem solucionado eficientemente o acesso a bens e a serviços de saúde; ao contrário, tem dado a esse conceito um sentido reverso, em que poucos podem ter acesso aos Tribunais para obter uma sentença. Este artigo examina a mediação sanitária como possibilidade de efetivar o direito à saúde, ressignificando os conflitos a partir da teoria de Eligio Resta - Diritto Vivente, o lado quente do Direito, que se opõe ao Direito pressionado pela urgência que desconsidera o que lhe é mais essencial, o vivente.

Palavras-chave: Mediação. Mediação sanitária. Direito à saúde. Diritto vivente. Conflito sóciossanitário.

\section{HEALTH MEDIATION, A LOOK AT THE RIGHT TO HEALTH IN LIGHT OF THE DIRITTO VIVENTE}

\begin{abstract}
Jurisdiction has not efficiently resolved access to health goods and services; on the contrary, it has given this concept a reverse meaning, in which few can have access to the courts to obtain a judgment. This article examines sanitary mediation as a possibility of realizing the right to health, resignifying conflicts based on the theory of Eligio Resta - Right Living, the hot side of law, which opposes the law pressured by the urgency that disregards what is more essential to it, the vivente.
\end{abstract}

Keywords: Mediation. Health Mediation. Right To Health. Diritto Vivente. Social-Health Conflict.

\section{Introdução}

Este artigo tem por objetivo discutir os conflitos jurídicos no âmbito do direito à saúde. Para tal, faremos uma reflexão sobre a importância do instituto da mediação ser mais

\footnotetext{
${ }^{1}$ Professora Produtividade CNPq, Pós Doutora em Direto pela Università de Roma Tre, Pós Doutora em Política Públicas pela Università do Salento. Professora e Coordenadora do Mestrado em Direitos Humanos da UniRitter e Professora Visitante no PPGDIR/UFRGS.

2 Mestranda em Direitos Humanos da UniRitter - Laureate Internacional Universities. Bolsista CAPES. Especialização em Direito Público pela Fundação Escola Superior do Ministério Público - RS, FESMP/RS, Brasil.
} 
bem aproveitado no âmbito jurídico-sanitário, assim consolidando o que denominamos mediação sanitária.

A mediação sanitária como opção ao processo judicial na resolução de litígios na saúde continua sendo raro; porém representa uma forma adequada para a solução de uma das mais relevantes demandas judiciais no Brasil, a área da saúde que ocupa posição de destaque nos processos de judicialização.

Para abordar tal problemática, utilizaremos fundamentalmente três autores e suas respectivas teorias, Warat, Resta e Luhman.

No primeiro ponto do artigo, o tema será a mediação como forma de resolução de conflitos bem como a legitimação do procedimento da mediação; discutiremos também a ideia e a importância da autocomposição desenvolvida por Warat. A seguir, refletiremos sobre aspectos relevantes da mediação sanitária, tendo como referência a Constituição Federal para discutir a questão da judicialização/desjudicialização da saúde. O pano de fundo teórico da mediação sanitária está na metateoria do Direito Fraterno, a qual como metateoria engloba várias teorias.

Com o objetivo de aprofundar as teorias, as técnicas de pesquisa utilizadas foram a bibliográfica em complemento à metodologia dedutiva.

\section{Mediação, forma de resolução de conflitos}

A Constituição Federal de 1988 trouxe, no âmago de seus objetivos fundamentais, a previsão da construção de uma sociedade baseada na fraternidade, livre de preconceitos, de desigualdades regionais e comprometida com o ideal de estabelecer um bem comum, voltada à consolidação de uma sociedade livre, justa e solidária.

Os ideais iniciais da Constituição Federal são aportados pela Revolução Francesa, e identificam os primados básicos para a consolidação do Estado Democrático de Direito: liberdade, igualdade e fraternidade. Os dois primeiros conceitos são amplamente estudados pela doutrina política e jurídica, associando-se, conforme propõe Bonavides (2002), à liberdade, ao desenvolvimento do Estado Liberal de Direito, e a igualdade ao desenvolvimento do Estado Social de Direito. 
No entanto, houve menos atenção com o conceito de fraternidade, considerado valor imprescindível à reestruturação dos institutos e das práticas jurídicas. Cabe ressaltar, nesse sentido, que a análise de um processo jurídico sob a ótica da fraternidade já pressupõe que nele sejam contempladas a liberdade e a igualdade e que agentes que nele atuam sejam fomentadores das práticas fraternas das suas decisões.

Elígio Resta (2008) propõe que o ideal democrático se concretizará se for respeitado o princípio da fraternidade, pois nas relações humanas e nas relações jurídicas esse princípio parte da premissa de que os indivíduos de um meio social possuem autorresponsabilidade sobre seus atos de modo que devem ter a oportunidade de participarem da solução dos conflitos existentes entre eles.

Tal proposta baseada no direito fraterno, além de admitir a participação das partes, em verdade as situa como colaboradoras do Estado no desenvolvimento da resolução de conflitos, afastando o conceito perdedor versus ganhador, que há muito orienta a justiça brasileira.

A mediação ${ }^{3}$, baseada no direito fraterno, por si só propõe a quebra de paradigmas possibilitando entender como incidem e quais as consequências da fraternidade nas relações sociais, o que inclui as relações jurídicas. É nesse sentido que a humanidade precisa superar a ausência de preocupação do bem comum e o menosprezo dos direitos inerentes à existência humana. Tal perspectiva fraterna traz um novo referencial para a ciência do Direito, que tem por fundamento outras áreas do conhecimento humano como a filosofia, a antropologia e a sociologia. Ou seja, o Direito fraterno pressupõe uma nova percepção de análise dos fatos sociais, produzindo efeitos também em seu sentido jurídico (VIAL; CAON; MINETO, 2004).

É possível perceber que ao tratar das consequências práticas do Direito fraterno, aplicado no meio social, Resta (2008) propõe uma visão comunitária, uma sociedade fundamentada na essência humana e uma Constituição sem inimigos e sem povo, no sentido de alcançar toda a coletividade humana em uma única vinculação fraterna. A construção desta

\footnotetext{
${ }^{3}$ Mediação é a atividade que a partir de seu deus, mensageiro dos deuses (e deus, não por acaso, do commercio, da comisuração das mercadorias), ganha o nome de hermenêutica. Arte da interpretação por excelência: preside à decifração das mensagens, decide sobre compatibilidade linguística. Mas é sobretudo tradução, de uma língua a outra. Sua sabedoria está no conhecer as duas línguas e operar a metaphorikòs. Nem mais nem menos, trata-se de uma metáfora e um meio de transporte: juntos, lugar e instrumento de uma metànoia, de uma metabolização. É o que pedimos à media, quando for capaz de nos imunizar da imediatez da violência (RESTA, 2008, p. 106107)
} 
comunidade depende, para Resta (2008), da superação de uma sociedade baseada na inveja e no individualismo, rumo à cultura social cooperativa e colaborativa do agir fraterno.

A visão hobbesiana de necessidade de ação estatal com base na conflituosidade inerente ao homem deve ser ultrapassada para se seguir uma proposta de Direito fundamentada na solidariedade, fraternidade, no compromisso mútuo entre comunidade e indivíduo para construção do bem comum.

Nesse sentido, Elígio Resta (2008) imprimiu visões fraternas como norteadoras das relações humanas na Teoria do Diritto Vivente, obra que apresenta a aproximação entre a ciência do Direito e a fraternidade. É com base nessa aproximação que Resta (2008) situa o instituto da mediação:

indica entre os valores extremos o ponto de e interseção entre um e outro. Representa o que os extremos compartilham. A mediação está ali, no meio, no ponto da co-divisão, no lugar "comum", é "senso comum", a partir do qual se pode reelaborar o que dividia e paranoicamente se perpetuava com a cumplicidade rival (RESTA, 2008, p.107).

No Direito brasileiro, a mediação representa uma forma de resolução de conflitos ancorada pelos princípios da confidencialidade, do respeito, da oralidade, da informalidade, da isonomia entre as partes, da autonomia da vontade das partes, da boa-fé, da imparcialidade do mediador. Na Comunidade Europeia também se desencadeou uma política para valorização da solução consensual de conflitos, com a criação da Diretiva 2008/52 que conceitua mediação ${ }^{4}$ como "um procedimento estruturado, seja qual for seu nome ou denominação, em que duas ou mais partes em litígio tentam voluntariamente alcançar por si mesmas um acordo sobre a resolução de um litígio com a ajuda de um mediador" (UNIÃO EUROPEIA, 2008, p. 6).

Ambas as propostas geraram mudanças na cultura judiciária e reforma nos sistemas de justiça, atuando de modo a remover os obstáculos que conduzem à ineficiência dos Tribunais. Fruto dessas mudanças, a mediação passa a influenciar de maneira significativa o ordenamento interno no tratamento dos conflitos, provocando a abertura de horizontes no enfrentamento da judicialização.

\footnotetext{
4 'Mediation' means a structured process, however named or referred to, whereby two or more parties to a dispute attempt by themselves, on a voluntary basis, to reach an agreement on the settlement of their dispute with the assistance of a mediator. This process may be initiated by the parties or suggested or ordered by a court or prescribed by the law of a Member State.
} 
Luis Alberto Warat (2004), voltado ao ensinamento de que é preciso sentir a si mesmo para sentir o outro, considera a mediação como a melhor forma para superar o imaginário do normativismo, indo além da positividade jurídica ao consagrar a busca por uma solução amigável do conflito por meio de um processo participativo. Sustenta o autor que "a mediação é uma forma ecológica de resolução de conflitos sociais e jurídicos, uma forma na qual o intuito de satisfação vital substitui a aplicação, coercitiva e terceirizada, de uma sanção legal” (WARAT, 2004, p.65). Na percepção waraniana, "na mediação a autocomposição é ecológica por duas razões".

\begin{abstract}
A primeira porque ela pode ser considerada como uma forma de realização da autonomia, na medida em que educa, facilita e ajuda na produção das diferenças (produção do tempo com o outro), que modificam as divergências. A autonomia, como a democracia, o amor e o ódio são formas de convivência com a conflitividade, com a incompletude que a conflitividade existencial determina. $\mathrm{O}$ indivíduo autônomo precisa negociar com o outro a produção conjunta da diferença, o que implica, forçosamente, a mediação do simbólico. Em segundo lugar, [...] porque ao procurar uma negociação transformadora facilita uma considerável melhoria na qualidade de vida (WARAT, 2004, p.59).
\end{abstract}

Esse entendimento consiste em reconhecer no instituto da mediação um componente essencial que permite aos mediandos analisarem, ponderarem e, se possível, equacionarem o conflito de tal forma, que consigam chegar à melhor solução para todos os envolvidos. A autocomposição do conflito e sua revisão pelos envolvidos possibilitam a construção da autonomia e o direito à outridade, "à revalorização do outro do conflito em detrimento do excessivo privilégio outorgado aos modos de dizer do direito, o litígio" (WARAT, 2004. p. 62.). Tanto para Resta quanto para Warat a mediação busca uma visão não dualista, uma proposta de julgamento que está além do bem e do mal.

Ao resgatar tais valores, a mediação estabelece uma nova visão da cidadania, dos direitos humanos e da democracia, que empodera individual e socialmente o cidadão a exercer o direito - que lhe cabe - de buscar um resultado justo na resolução de conflitos. No modelo tradicional - juiz e partes -, a democracia, correlacionada ao exercício da cidadania, pode não estar presente, pois os envolvidos por vezes não são ouvidos, nem participam da construção das soluções das suas demandas.

Como destaca Sarlet (2014) proteção aos direitos sociais em sua condição subjetiva tem servido para "imprimir à noção de cidadania um novo contorno e conteúdo, potencialmente mais inclusivo e solidário”. Empoderamento do indivíduo e crescimento 
socialmente inclusivo, vale lembrar, são os dois elementos mais relevantes no desenvolvimento de uma nação.

Segundo Luhmann, a mediação responde às expectativas dos integrantes e abre espaço para a melhor forma de decidir e sentir o conflito a partir da diferença que figura como instrumento de construção de um outro. $\mathrm{O}$ autor argumenta que o procedimento da mediação se legitima quando a diferenciação e a autonomia abrem espaço para a plena atuação dos participantes, reduzindo a complexidade. Como instrumento ocasionador da autonomia, permite que só os participantes possam:

\begin{abstract}
ser motivados a controlarem, eles próprios, os riscos da sua ação, a cooperarem, sob controle, na absorção da incerteza e dessa forma a contraírem gradualmente um compromisso. Até onde leva este mecanismo, até onde ele pode implicar uma reestruturação das expectativas e com ela a legitimação da decisão - é um problema que temos que enfrentar [...] (LUHMANN, 1980, p. 64).
\end{abstract}

Assim, a mediação pode resgatar relações contaminadas pela atuação de operadores direito que, em tese, deveriam exercer suas funções desprendidas de qualquer pré-conceito. Luhmann alerta que muitos juízos são formados com base em uma visão funcionalista, em que o indivíduo é um mero elemento funcional no corpo social, sem direitos inerentes à sua existência, mas inerentes ao seu agir: se agir bem, ele é valorizado; se agir mal, é desprezado (LUHMANN, 1998).

$\mathrm{Na}$ verdade, é uma visão reducionista guiada pelo isolacionismo dos indivíduos na sociedade, pela ausência de tolerância e de vínculos de solidariedade entre eles. A consolidação da solidariedade, da fraternidade depende da conscientização de cada indivíduo, para que a partir daí possa guiar suas ações em sociedade, referindo assim mesmo como integrante da fraternidade humana.

Com base nesses fundamentos, acrescidos do estímulo à confiança, ao respeito entre as partes envolvidas na relação processual, pode-se considerar a mediação como um instrumento valorativo útil para transformação da visão processualista atual. É esse o caminho a ser percorrido pelo Direito brasileiro como consta no preâmbulo da Constituição Federal, fomentando a construção de relações baseadas nos valores propostos pela teoria de Eligio Resta. 


\title{
3 Mediação sanitária
}

A mediação sanitária possibilita transformações nas condições que afetam a qualidade de vida dos cidadãos e apresenta-se como um possível instrumento de regulação social na área da saúde, empoderando o cidadão a responsabilizar-se pela melhoria da condição de vida em nível individual e social. Isso representa um ideal de cidadania realizado pela mediação, conforme indica Luís Alberto Warat:

\begin{abstract}
A cidadania está reduzida a indivíduos que participam indiretamente na produção das decisões do Estado, para logo delegar-lhe a missão de decidir seus próprios conflitos. É um cidadão que renuncia a administrar seus próprios conflitos, porque foi forçado a crer que era melhor que o Estado, que ele ajudava indiretamente, fosse o que tomasse medidas coercitivas sobre suas próprias situações de insatisfação. [...] Chegou a hora de devolver à cidadania e aos Direitos Humanos suas possibilidades de humanizar nossa relação com os outros, principalmente, por intermédio de um Direito comprometido com a humanização de suas funções nos conflitos, o Direito da mediação (WARAT, 2001, p. 16).
\end{abstract}

A Constituição Federal, 1988, estatuiu no art. $196^{5}$ que é dever do Estado garantir a saúde física e mental dos indivíduos; e deixa claro que, para além do direito fundamental à saúde, há o dever fundamental de prestação de saúde por parte do Estado (União, Estados, Distrito Federal e Municípios). Em razão da garantia constitucional, há uma enorme demanda de atendimentos na área da saúde, e tem se tornado cada vez mais nítido o descontentamento de quem utiliza as redes de saúde pública no Brasil. Cabe indagar quais medidas são necessárias para suprir a falta de recursos para uma adequada assistência à saúde.

$\mathrm{Na}$ área da saúde, a jurisdição por vezes não é capaz de dar solução adequada a certos tipos de conflito por desconhecer o campo do conhecimento do tema posto a seu julgamento, ou por apenas exercer a função jurisdicional de aplicação da lei ao caso concreto (DELDUQUE; CASTRO, 2015), afirmando-se na função substitutiva do sistema político e “destecnificando" a aplicação da lei. Por consequência, leva-se à judicialização da vida administrativa e econômica (FARIA, 2004), perpetuando na área da saúde um contexto de injustiça, em desencontro com o ambiente democrático que assegura amplos direitos de cidadania.

\footnotetext{
${ }^{5}$ A saúde é direito de todos e dever do Estado, garantido mediante políticas sociais e econômicas que visem à redução do risco de doença e de outros agravos e ao acesso universal e igualitário às ações e serviços para a promoção, proteção e recuperação (Constituição Federal, art. 196).
} 
Cappelletti e Garth $(1988$; 1996) dividiram em três ondas os principais movimentos renovatórios do acesso à justiça. A primeira onda diz respeito à assistência judiciária aos pobres e está relacionada ao obstáculo econômico do acesso à justiça. A segunda onda referese à representação dos interesses difusos em juízo e visa contornar o obstáculo organizacional do acesso à justiça. A terceira onda, denominada de "o enfoque do acesso à justiça", detém a concepção mais ampla de acesso à justiça, e tem como escopo instituir técnicas processuais adequadas e melhor preparar os aplicadores do direito.

\begin{abstract}
A primeira onda renovatória se referia à ampliação de acesso ao judiciário, concedendo a assistência judiciária aos pobres, por meio da remoção das barreiras econômicas. A Constituição Federal de 1988, em seu art. 5º, LXXIV, ao determinar que "o Estado prestará assistência jurídica integral e gratuita aos que comprovarem insuficiência de recursos", demonstra essa preocupação.

Já a segunda onda objetivou a proteção dos interesses difusos (proteção ambiental, do consumidor, etc...). Por último, a terceira onda renovatória apresentou um novo enfoque de acesso à justiça, até porque englobou perspectivas das duas primeiras ondas e buscou aprimorá-las, trouxe uma concepção mais ampla, cujo ponto central era a utilização de técnicas alternativas de resolução de conflitos, tais como a mediação, aumentando as opções de forma a tornar a justiça mais acessível e apropriada a cada situação fática apresentada.

Deve-se, portanto, romper com o dogma de que apenas o Poder Judiciário é capaz de garantir o "acesso à justiça", para demonstrar que esta pode ser alcançada por instrumentos não judiciais, em tempo razoável e de modo efetivo, como, por exemplo, por meios autônomos de solução de conflitos de interesse. Os órgãos judiciais, nesse sentido, representariam ferramenta subsidiária, em contrapartida ao amadurecimento dos jurisdicionados (CASCARDO, 2016, não paginado).
\end{abstract}

Pergunta-se: o que a terceira onda tem a ver com a judicialização da saúde e o movimento universal de acesso à justiça? De acordo com Antônio Hermam V. Benjamin, a expressão acesso à justiça pode ser definida de três formas:

I) em sentido restrito, diz respeito ao 'acesso à tutela jurisdicional' de direitos acesso a um juiz natural para a composição de litígios; II) em sentido mais amplo, embora insuficiente, refere-se ao 'acesso à tutela', jurisdicional ou não, de direitos acesso a mecanismos de solução de conflitos, judiciais ou extrajudiciais; e III) em acepção integral, significa 'acesso ao Direito' - acesso à ordem jurídica justa, conhecida e implementável (BENJAMIN, 1995, p.77).

Entre os modelos alternativos de resolução de conflitos na área da saúde, na mediação sanitária transcendem-se a ótica bilateral médico e paciente, para envolver muitos outros atores presentes em um sistema de saúde. Advêm, daí, conflitos de toda a ordem, 
internos e externos ao sistema, criando condições para a judicialização ${ }^{6}$. Conflitos internos (como os assistenciais, organizativos e conflitos entre profissionais) geram desgastes e judicialização, como também fazem os conflitos gerados fora do sistema - mas com reflexos diretos dentro dele -, os conflitos sociais e os conflitos legais (DELDUQUE, 2015).

Sob o ponto de vista jurídico, a autonomia na relação médico-paciente transcende a forma meramente contratual de declaração da vontade porque se refere a um bem extrapatrimonial. A disposição do indivíduo sobre o próprio corpo torna essa relação horizontal, deixando para trás a visão do paciente como mero espectador e do médico como senhor absoluto de decisões. Não significa que as limitações do respeito à autonomia com caráter protetivo devam deixar de existir.

Nas questões de saúde, como já mencionado, os magistrados não se sentem confortáveis em adotar a solução apontada pela simples aplicação da lei, pois apresentam uma grande dificuldade em fundamentar a decisão com base em preceitos técnicos - jurídicos (ZEBULUM, 2017, p.162). Com horizonte na adequação aos limites de aplicação e na amplitude social do Direito Sanitário, surge a mediação sanitária que, além de possibilitar que se abra um menor número de processos judiciais, tem uma "proposta reformadora, moderna, democrática e solidária e de necessidade evidente na construção do direito à saúde, de forma integral, universal, igualitária e humanizada” (ASSIS, 2013, p. 471).

\section{Diritto Vivente}

Tendo em vista a dinâmica da sociedade e a forma como são encarados os conflitos, ganha espaço o Diritto Vivente ${ }^{7}$ - direito vivo - um direito que "olha a vida da norma no tempo e espaço. Não é uma leitura literal da norma, mas da sua aplicação. É neste aspecto que o direito ganha vida e se torna animado" (DAMACENA; WEBBER, 2018, p. 100).

O Direito interfere no modo de viver do indivíduo, e tem em sua essência o condão de resguardar a vida, porém em determinadas situações não consegue atender às necessidades da

\footnotetext{
${ }^{6}$ A leitura do relatório Justiça em Números de 2017, do Conselho Nacional de Justiça (CNJ) (JUSTIÇA..., 2017), permite observar que há 1.346 .931 demandas em tramitação (SHULZE, 2018, p.143).

${ }^{7}$ Diritto vivente significa "direito animado", que vive e tem vida, que olha a vida da norma no tempo e no espaço. Não é uma leitura da norma, mas da sua aplicação. Neste aspecto que o direito ganha vida e se torna animado (DAMACENA, HOHENDORFF, MOLIN, 2017).

É o Direito que se apresenta de um modo, mas poderia se apresentar de outro, que tenta regular o próprio direito, quando não consegue regular nem o Direito nem a vida em sociedade (DAMACENA, WEBBER, 2018).
} 
sociedade, em outras pode tornar sua existência ameaçada porque não observa ( ou se observa, não contempla ) valores morais inerentes ao ser humano. “A moral não está catalogada, contrário está o Direito com toda sua norma positivada e ultrapassada, o que exige uma profunda reflexão para que o próprio Direito se mantenha "vivo" no contexto contemporâneo". (FOREST; VIAL, 2014)

No entendimento de Eligio Resta, o Diritto Vivente tem como pressuposto o tempo e a técnica. A técnica, na perspectiva vivente, “opera dentro da sociedade e proporciona diversos questionamentos, tais como os limites impostos pelo Direito, as qualidades das decisões emanadas pelo Direito, que devem ser preventivas e proativas". O tempo, na dimensão vivente, "enfrenta a emergência e a exceção, a partir das noções de regulação, contratempos e complexidade" (DAMACENA; WEBBER; 2018, p. 99). Segundo Resta,

\begin{abstract}
O acoplamento estrutural entre tempo e paixões é exatamente o que o sistema social impôs. Um exemplo que emerge do estudo dos sistemas normativos é o do matrimônio. A institucionalização do matrimônio ocorre, na sociedade ocidental, muito tarde, quando se torna por demais explícita a lacuna existente entre o tempo das paixões individuais e a estabilidade dos vínculos. O tempo do amor, sabe-se, pode não coincidir com o tempo da organização formalizada das relações; ao menos, tudo é contingente, mas a partir do momento em que o contraste pode ser mais forte entre a imprevisibilidade e instabilidade das paixões, de um lado, e a previsibilidade e estabilidade dos vínculos organizativos, de outro, o sistema social começa a codificar a intimidade. E o faz somente quando entende tal contraste como problema. Em poucas palavras, afirma que, para o sistema social, se dois se amaram uma vez, amar-se-ão por toda a vida. (RESTA, 2008, p.120).
\end{abstract}

No Direito sanitário, o acoplamento estrutural entre o tempo e o direito à saúde é extremamente delicado. O tempo do direito à saúde não coincide muitas vezes com o tempo das organizações sanitárias. No Brasil são diversos problemas sofridos pela população na área da saúde; com frequência significativa, hospitais e demais serviços de saúde enfrentam problemas como falta de médicos, leitos, materiais cirúrgicos e desabastecimentos de medicamentos, entre outros. O que quer que seja, todas as necessidades, na saúde são prementes, não podendo deixar o tempo corroê-las. Na análise de Resta a ordem do tempo é "uma ordem apenas aparentemente autoritária, deixando em aberto todas as possibilidades, ou seja, deixando em aberto o mundo da contingência. É generalização congruente (nomos) que espera a liberdade dos acontecimentos e é ali que o paradoxo é resolvido enquanto continua a ter seu lugar" (RESTA, 2008, p. 120).

O direito à saúde é um direito que deve ser analisado na ótica democrática para que possa existir um equilíbrio entre os valores da liberdade e da igualdade. Nesse sentido, a 
observação do tempo no direito sanitário deve observar e pressupor a fraternidade, a soliedariedade, a segurança, a estabilidade, como uma forma de inclusão do direito à saúde frente uma realidade social em constante mutação. Como advertem Clam, Rocha e Schwartz (2017), “a instabilidade e a insegurança ressoam como ruídos que precisam ser "normalizados"a partir da autopoiese do Direito, dentro das possibilidades de sistema funcionalmente diferenciado que é". Essas considerações não invalidam que "a gestão do tempo deve ser orientada pelo repeito às Constituições e aos Direitos fundamentais" (DAMACENA; HOHENDORFF; MOLIN, 2017).

O Direito, exatamente como a técnica, regula o mundo estando dentro dele, colocando-se como dispositivo válido para um todo sendo parte do todo; e assim, deve mas não pode ou pode mas não deve (RESTA, 2008, p. 84). Na mesma medida em que o Direito precisa da vida, em inúmeras circunstâncias proporciona sua morte. Essa situação pode ser facilmente vislumbrada quando não se permite que um Direito, com outros fundamentos como os do Vivente, efetivamente seja o decidido e julgado. Neste contexto, temos o Direito "morto", o da lei, da regra, pura e simplesmente, sem contato com o vivo. A difícil busca da incorporação da vida no Direito é exatamente o que persegue o Diritto Vivente, descrito por Resta.

A vida, bios do vivente, parte do Direito, traz à reflexão uma situação carregada de paradoxalidade - vida/morte. Eligio Resta desenvolve essa questão a partir da ideia phàrmakon, máximo lugar da ambivalência, em que condensa todo o sentido da lei platônica, veneno e antídoto, injustiça e justiça, vítima e carrasco, e sobretudo corpo e alma. (RESTA, 2008, p. 12).

Resta retoma o discurso platônico ao definir que "um corpo separado de sua physis (alma), uma lei da sua razão, uma polis de seu nomos, serão destinados a condenar Sócrates: o seu, como se sabe, é o processo à razão" (RESTA, 2008, p. 13).

A possibilidade de que os homens governem sem se entregarem ao primado da lei, que tudo seja decisão contingente e particularística, que a justiça seja injusta de um lado e caridosa de outro, são possibilidades contempladas e sabiamente reconhecidas no discurso platônico (RESTA, 2008, p. 13).

O Direito não deve apenas agir após o fato, como elemento corretivo. Deve agir como um elemento integrativo, reagindo de forma diferente da tradicional frente aos novos desafios provenientes de uma realidade, ainda não contemplada pelo Direito tradicional. Essa 
é a razão do surgimento do "Direito Vivo", um discurso que vem ganhando espaço nas últimas décadas, pelas numerosas dicotomias decorrentes de uma cultura jurídica que insiste em margear a enorme complexidade jurídica atual. Eligio Resta sustenta que o "jogo singular aquele do Direito e da vida: razão de aproximações e distanciamentos, de representações e condensações, de referências puras e incorporações" (RESTA, 2008, p. 3).

Tendo como guia o Diritto Vivente, vida, dignidade e saúde coexistem e ocupam o mesmo espaço, pois para atingir o almejado bem-estar, não faz sentido dissociá-las. Uma vida sem dignidade não passa de uma mera existência, e dignidade sem saúde é algo impensado para o abrangente conceito de vida. Para Resta,

\begin{abstract}
O verdadeiro problema não é tanto quem decide e como, mas o que se chamou a decidir. O verdadeiro conflito está no interpretar as possibilidades oferecidas pela tecnologia como mais ou menos correspondentes aos valores reflexivos indicados pelo direito. O que é dignidade humana, morrer sem sofrimentos ulteriores ou sobreviver através de uma obstinação médica que deixa em aberto o impossível princípio esperança? No mais, quanta "esperança" temos e qual é o "tempo" previsível desta "paixão negativa"? A dimensão da dignidade, como princípio, deixa aberta as possibilidades, poupa o direito, mas torna obviamente mais trágica e mais solitária a decisão (RESTA, 2008, p. 75).
\end{abstract}

Nesse sentido, a questão que merece ser destacada é a de que o que equipara Direito e técnica não é a lógica do poder, mas da ambivalência que vive da cumplicidade dos contrários: bom/mau, justo/injusto, permitido/proibido, lícito/ilícito. Na opinião de Resta,

\begin{abstract}
A partir dos polos da oscilação não se escapa optando por um valor "terceiro" (se fosse possível não estaríamos em uma condição trágica porque indecidível) nem um "terceiro" à decisão (como em regra fazemos quando remetemos tudo a um "juiz"), mas se elaborando com mais profundidade e conscientemente a ecologia da decisão. A técnica, como o direito, vive e opera dentro da sociedade: trabalha hermeneuticamente abrindo possibilidades "dadas" pela compatibilidade e pela inevitável busca de universalismo (RESTA, 2008, p.76).
\end{abstract}

Por esse ângulo, analisam Damacena e Webber (2018, p. 08):

a vida do direito é compreendia entre os dois polos da ambivalência; sua história é de justas doses a se buscar entre os dois opostos, história jamais concluída, que precisa confiar, às vezes na prudência, racionalidade, na força dos sujeitos em jogo, na técnica normativa e na experiência judiciária. 
Interessa destacar que essa polarização é determinante para eclosão de novas ideias, uma proposta baseada em uma construção de novos sentidos, de evolução, inspirado na harmonia entre os que integram o todo. Assim considera Resta,

\begin{abstract}
Não é por acaso que muitos sentidos venham do conhecimento jurídico e da sua técnica de imunização dos conflitos. A figura do juiz é aquela do terceiro estranho ao conflito que diz a última palavra (ius dicere) graças a uma metalinguagem capaz de recompreender e julgar sobre linguagens. $\mathrm{O}$ terceiro se reivindica competente exatamente porque estranho e superior às razões dos contendores em jogo. Sua neutralidade é importante, mas nela não se pode tudo remeter, sob risco de abstração. A mediação é algo de metabólico porque vive no mesmo ambiente dos conflitos que se produzem, devendo estar entre os conflitantes, e não estranha e separada (RESTA, 2008, p.107).
\end{abstract}

Conhecer a teoria do Diritto Vivente, inscreve-se na ressignificação do direito à saúde, permitindo um caminho para entender a origem dos conflitos sanitários, implicando uma nova visão para o domínio efetivo do Direito.

\title{
5 Considerações finais
}

O presente trabalho buscou dar um olhar ao direito sanitário à luz do Diritto Vivente por meio da mediação sanitária. $\mathrm{O}$ direito à saúde é um dos principais direitos reconhecidos no Brasil, tendo importante destaque na Constituição Federal, que define a saúde como um direito social fundamental, de caráter universal, assegurado pelo Estado, e efetivado por intermédio de políticas sociais e econômicas. Sabemos que a implantação desse fundamental direito à saúde, impõe enormes desafios, principalmente quando consideramos o acesso universal da saúde pela população brasileira acima de 203 bilhões de habitantes.

De acordo com dados do CNJ, em 2017 o número de processos foi alarmante, em torno de 1.346 .931 processos na área da saúde. Percebe-se que a jurisdição precisa ser revisada, e, assim, exigem-se novas alternativas de resolução de conflitos. Surge, dessa forma, a mediação sanitária como um meio inovador e eficaz de resolução de controvérsias.

Ficou demonstrado que a mediação sanitária é um poderoso instrumento, pois permite a interação democrática entre os participantes, reduz o número de tensões e conflitos na área da saúde, permitindo efetivação social do direito à saúde. 
A partir da construção do conceito de pharmakon, proposto por Eligio Resta, ficou evidente que as decisões que são tomadas por um terceiro, principalmente pela escolha da sua dosagem muitas vezes incorrem em resoluções pouco acertadas. O juiz é obrigado a decidir pelo certo/errado, pelo bom/mal, pelo justo/injusto, ficando atrelado à moldura da lei - o lado frio do Direito.

Na perspectiva de um Direito voltado para o futuro, o Direito fraterno está apto a construir um pacto jurado em conjunto por irmãos, em oposição ao Direito paterno. Os indivíduos têm em comum as diferenças entre eles, assim é necessário encarar o outro numa política baseada na alteridade e na dignidade do ser humano, permitindo que cada indivíduo assuma o ponto de vista do outro e reconheça a sua identidade.

Como a vida representa o bem de maior valor que um ser humano possa ter, é preciso rever seu significado a partir de relações de fraternidade e afeto. A partir dessa ideia surge a mediação sanitária, como o lado quente do Direito. O Direito visto de uma forma fraterna, em que o outro é valorizado, respeitado, empoderado, equilibrando-se a relação, fazendo com que a VIDA seja realmente vista como um desafio a ser superado, a partir da compreensão de que somos responsáveis pela nossa VIDA e enxergamos o mundo de forma abrangente, mais conectado, mais amoroso.

\section{Referências}

ASSIS, Gilmar. A ação institucional de mediação sanitária: Direito, saúde e cidadania.

Revista de Cadernos Ibero-Americanos de Direito Sanitário, Brasilia, v. 2, n. 2, jul./dez. 2013. Disponível em:

https://www.cadernos.prodisa.fiocruz.br/index.php/cadernos/article/view/98/140. Acesso em 29 ago. 2019.

BENJAMIN, Antônio Herman V. A insurreição da aldeia global contra o processo civil clássico: apontamentos sobre a opressão e a libertação judiciais do meio ambiente e do consumidor. In: MILARÉ, Édis (coord.). Ação civil pública - Lei 7.347/85: reminiscências e reflexões após dez anos de aplicação. São Paulo: Editora Revista dos Tribunais, 1995.

BONAVIDES, Paulo. Curso de direito constitucional. São Paulo: Malheiros, 2002.

CAPPELLETTI, Mauro; GARTH, Bryant. Acesso à justiça. Porto Alegre: Sérgio Antonio Fabris, 1988. 
CAPPELLETTI, M.; GARTH, B. G. El acceso a la justicia: la tendencia en el movimiento mundial para hacer efectivos los derechos. Madrid: Fondo de Cultura Economica, 1996.

CASCARDO, Leonardo. A desjudicialização como ferramenta diferencial de acesso à Justiça: a desjudicialização como forma de acesso à justiça. JusBrasil, 19 maio, 2016. Disponível em: https://armelonicascardo.jusbrasil.com.br/artigos/339289050/a-desjudicializacao-comoferramenta-diferencial-de-acesso-a-justica. Acesso em: 31 jul. 2019.

DAMACENA, Fernada; HOHENDORFF, Raquel Von; MOLIN, Angela. Direito vivente: entre os tempos e contratempos da técnica. Revista da faculdade de Direito da Uerj, Rio de Janeiro, n. 32, dez. 2017. Disponível em:

https://pdfs.semanticscholar.org/015e/c370bb58c8a837106253d8e2e8fe1 cecc4e1.pdf? ga=2.2 59565901.692692426.1566129306-1942593271.1566129306. Acesso em 29 ago. 2019.

DAMACENA, Fernada; WEBBER, Suelen. Observações sobre o diritto vivente na sociedade complexa. Revista do Curso de Direito - FSG, v. 13, n. 22, 2018. Disponível em: http://ojs.fsg.br/index.php/direito/article/view/2920. Acesso em 29 ago. 2019.

DELDUQUE, Maria Célia. A Mediação Sanitária como novo paradigma alternativo à judicialização das políticas de saúde no Brasil. Conselho Nacional de Secretários de Saúde - CONASS, 2015, Disponível em

https://www.conass.org.br/biblioteca/pdf/colecao2015/CONASS-DIREITO_A_SAUDEART 9B.pdf. Acesso em: 29 ago. 2019.

DELDUQUE, Maria Célia; CASTRO, Eduardo Vazquez de. A Mediação Sanitária como alternativa viável à judicialização das políticas de saúde no Brasil. Saúde debate [online], v. 39, n. 105, p. 506-513, 2015. Acesso em:

http://www.scielo.br/scielo.php?script=sci arttext\&pid=S010311042015000200506\&lng=pt\&tlng=pt. Acesso em: 29 ago. 2019.

FARIA, J. E. O sistema brasileiro de Justiça: experiência recente e futuros desafios. Revista de Estudos Avançados, São Paulo, v. 51, n. 18, p. 103-125, 2004. Disponível em: http://www.revistas.usp.br/eav/article/view/10002/11574. Acesso em 29 ago. 2019.

FOREST, Rosane; VIAL, Sandra Regina Martini. O direito à morte digna no contexto do Direito Sanitário. Cad. Ibero-Amer. Dir. Sanit., Brasília, v.3, n.3, out/dez. 2014. Disponível em: https://www.cadernos.prodisa.fiocruz.br/index.php/cadernos/article/view/54. Acesso em 31 ago. 2019.

JUSTIÇA em números 2017: ano-base 2016. Brasília: CNJ, 2017. Disponível em: https://www.cnj.jus.br/files/conteudo/arquivo/2017/12/b60a659e5d5cb79337945c1dd137496c .pdf. Acesso em 29 ago. 2019.

LUHMANN, Niklas. Legitimação pelo procedimento. Brasília: UNB, 1980.

LUHMANN, Niklas. Complexidade e modernidade: da unidade à diferença. Madrd: Trota, 1998. 
RESTA, Eligio. Diritto vivente. Bari: Laterza, 2008.

SARLET, Wolfgang Ingo. Direitos fundamentais a prestações sociais e crise: algumas aproximações. EJJL, Joaçaba, v. 16, n. 2, p. 459-488, jul.-dez., 2015. Disponível em: http://repositorio.pucrs.br/dspace/bitstream/10923/11320/2/DIREITOS_FUNDAMENTAIS _ A_PRESTACOES_SOCIAIS_E_CRISE_ALGUMAS_APROXIMACOES_FUNDAMENTA L RIGHTS TO SOCIAL BENEFITS AND.pdf. Acesso em 31 ago. 2019.

SHULZE, Clenio Jair. A judicialização da saúde no século XXI. Porto Alegre: Verbo Jurídico, 2018.

UNIÃO EUROPEIA. Directiva 2008/52/CE del Parlamento Europeo y del Consejo, de 21 de mayo de 2008, sobre ciertos aspectos de la mediación en asuntos civiles y mercantiles. Diario Oficial de la Unión Europea, 2008. Disponível em: https://eur-lex.europa.eu/legalcontent/ES/TXT/PDF/?uri=CELEX:32008L0052\&from=EN. Acesso em 16 ago. 2019.

VIAL, Sandra Regina Martini; CAON, Liane Martins; MINETO, Daniela de Oliveira. Sociedade contemporânea: o paradoxo da inclusão/exclusão social no contexto da globalização. In Direitos Sociais e Políticas Públicas: desafios contemporâneos. Santa Cruz do Sul: EDUNISC, 2004.

WARAT, Luis Alberto. O Ofício do Mediador. Florianópolis: Habitus, 2001.

WARAT, Luis Alberto. Surfando na pororoca: ofício do mediador. Florianopólis: Fundação Boiteux, 2004.

ZEBULUM, José Carlos. Decisões judiciais em matéria de saúde: as conexões entre o direito e a moral. Revista Cadernos Ibero-americanos de Direito Sanitário, Brasília, v. 6, n. 1, p. 9-34, jan./mar. 2017. Disponível em: https://www.cadernos.prodisa.fiocruz.br/index.php/cadernos/article/download/355/442. Acesso em: 29 ago. 2019. 